\title{
SERUM TREATMENT OF HEMOLYTIC STREPTOCOCCUS PNEUMONIA
}

\author{
By HAROLD L. AMOSS AND ERLE B. CRAVEN, JR. \\ (From the Department of Medicine, Duke Unizersity Hospital and \\ Medical School, Durham)
}

(Received for publication May 9, 1933)

During the several outbreaks of respiratory disease occurring during the colder months of the year, the chance simultaneous occurrence of streptococcus tonsillitis not infrequently results in hemolytic streptococcus lobular pneumonia. Many of the cases of pneumonia seem to be secondary in the sense that the symptoms of an acute infectious disease such as influenza, measles, sinusitis, etc. are present for a few days before the onset of pneumonia; whereas, in a smaller number, there occurs a sudden onset of lobular pneumonia usually with pleurisy without any evidence of a preceding infection. The seriousness of both types of hemolytic streptococcus pneumonia with the high mortality and frequent occurrence of empyema is well known. The accepted method of treatment is supportive and symptomatic with surgical intervention whenever empyema occurs. The only hope of successful treatment lies in the use of specific agents. Since certain other streptococcal infections such as scarlet fever and erysipelas have apparently improved under the administration of specific antiserum, it is logical to apply these methods to the streptococcal pneumonias. At least one difficulty comes to mind immediately, viz.: the problem of preparing a serum of sufficient polyvalency to be generally applicable. The pathogenic hemolytic streptococci vary greatly in their antigenic values. Even the strains isolated from cases of erysipelas and cellulitis show considerable differences not only immunologically but in their fermentative reactions. ${ }^{1}$ However, these strains by their breadth of immunological reaction are apparently interrelated and it has been found possible by means of the Lancefield precipitation test to select nine strains for the production of a polyvalent serum sufficiently broad to cover all the strains thus far recovered from cases of erysipelas and cellulitis. This assumption of coverage is based on the Lancefield (1) M factor precipitin reaction in monovalent rabbit $^{2}$ sera prepared against each of the nine strains, on the neutralization of the toxallergin, on protection tests in mice and on clinical response in human cases.

\footnotetext{
${ }^{1}$ Unpublished experiments of Eleanor A. Bliss.

${ }^{2}$ It has not been found possible to obtain the precipitin reaction with serum from immunized horses.
} 
The first opportunity to apply this serum ${ }^{3}$ in the treatment of streptococcus pneumonia came before any immunological tests were carried out. But such tests coincidently with treatment were carried out, showing that the polyvalent serum possesses antibodies for the particular strain involved.

The purpose of this report is to record the details of the treatment of eight successive cases ${ }^{4}$ of $\beta$-hemolytic streptococcus pneumonia, all of whom recovered.

Casc I. I. D., female, aged twenty-one years, was admitted February 14, 1930, complaining of chills, fever and swollen cervical lymph nodes of nine days' duration. Past history: Frequent tonsillitis before tonsillectomy, twelve years ago, and a rather severe sinusitis one and a half years ago.

The illness for which she was admitted began simply enough as a sore throat and head cold, with rather marked swelling of the lymph nodes and later fever.

For a week the temperature was normal every morning, reaching $39.5^{\circ}$ and $40^{\circ} \mathrm{C}$. at night, with profuse sweats and later with pain over the right side of the face. On admission she appeared moderately ill and showed little except the red pharynx, the tenderness over the right maxillary frontal sinus and general moderate lymph node enlargement. Her temperature was $39.7^{\circ} \mathrm{C}$.; pulse 138 ; blood pressure 130 systolic and 80 diastolic; her leukocytes were 17,600 with 54 per cent polymorphonuclears. The urine showed red and white cells and $2+$ albumin.

At this time she was found to have an acute right maxillary sinusitis and a mild acute nephritis. Despite puncture of the antrum, four days later her temperature continued to fluctuate widely from $36.5^{\circ}$ to $40.5^{\circ} \mathrm{C}$. in the course of six hours. The urine contained red cells and albumin and the nonprotein nitrogen rose to $48 \mathrm{mgm}$. per cent. $\beta$-hemolytic streptococci were grown from the antrum washings. On the twenty-second day after onset she developed signs of pneumonia of the right upper lobe. Cultures and mouse inoculation of the washed sputum showed predominance of $\beta$-hemolytic streptococci, which by the Lancefield method yielded a specific soluble substance precipitated by monovalent antierysipelas serum. She was given two intravenous injections of antierysipelas serum, first $25 \mathrm{cc}$. and then $50 \mathrm{cc}$. Following this the temperature fell to normal and the excretion of urine rose from $560 \mathrm{cc}$. per day (average for seven days) to $2340 \mathrm{cc}$. the following day and continued at an average of 1460 cc. per day.

Her course was then uneventful, except for two moderate attacks of serum sickness. She began to gain in weight and strength. Her red count and hemoglobin began to return to normal. Her sinuses cleared and showed no further streptococci on culture, although her pharynx continued to harbor a decreasing number of these organisms. On the day of discharge a culture was negative.

The only abnormality was in the urine. The kidney function tests were normal, but there were continuously present great numbers of red cells and a

${ }^{3}$ Polyvalent antistreptococcus hemolyticus serum (unconcentrated) and its concentrated product (erysipelas antitoxin) prepared by H. K. Mulford Company using nine selected strains. In two cases streptococcus antitoxin prepared by the New York State Laboratory was used in addition.

${ }^{4}$ Abstract of the first five cases treated was presented before the Association of American Physicians in 1931 by Amoss, H. L., Persons, E. L., and Hansen Pruss, O. C. 
fair number of white cells as well as albumin, although the latter fell to a faint trace before discharge.

She was discharged March 19, 1930, six weeks after admission.

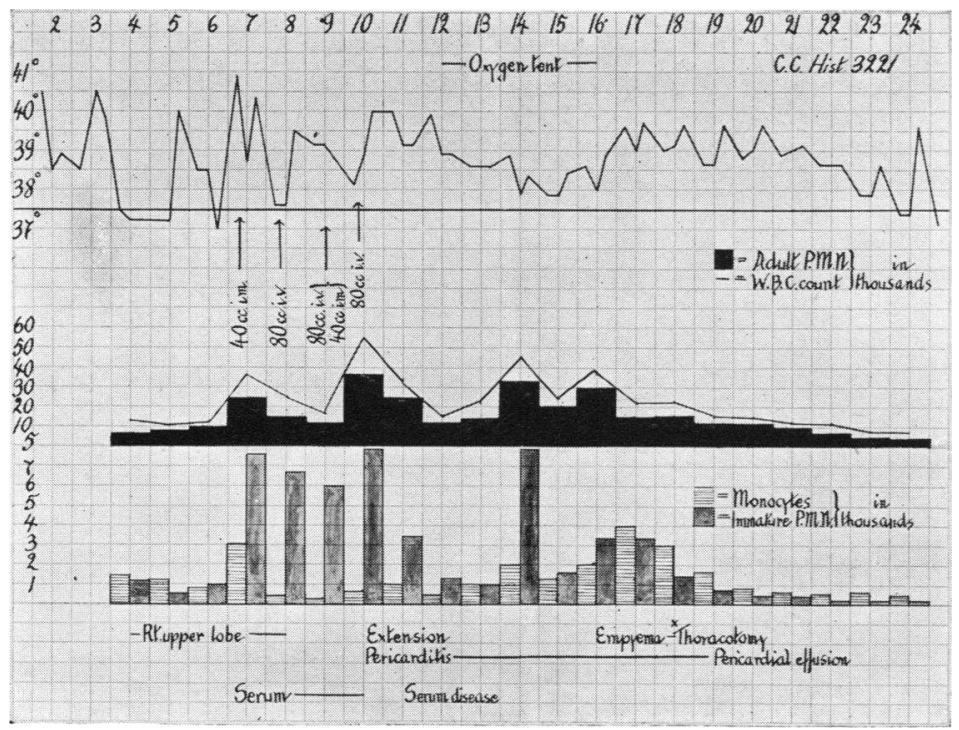

Chart I. Case II

Case II. C. C., male, aged twenty-two years, was well until February 2, 1931, when he had a sudden attack of high fever, headache, weakness, nausea, and vomiting and was admitted to the infirmary. Recovery was uneventful and he was discharged on February 7th. He was extremely weak and had severe night sweats but returned to school and work on February 12th. One week later he was readmitted to the infirmary with German measles, and remained four days. He did not return to work until February 24th. On the evening of February 28th, there was a sudden onset of high fever accompanied by aching, and he was readmitted to the infirmary on March 1st. For three days the temperature varied from $37^{\circ}$ to $40.5^{\circ} \mathrm{C}$., with two chills each day. On March 5th he was admitted to the hospital with signs of lobular pneumonia in the right upper lobe. The sputum culture showed innumerable colonies of $\beta$-hemolytic streptococci. The temperature fluctuated between $37^{\circ}$ and $41^{\circ} \mathrm{C}$. On the sixth day after onset the patient had two chills, seemed much worse, and complained of severe pain in the right side of his chest. In the afternoon 40 cc. of concentrated erysipelas serum were injected intramuscularly, and in the afternoon of the seventh day $80 \mathrm{cc}$. of the unconcentrated serum were given intravenously. These doses were repeated on the eighth day and the intravenous injection repeated again on the tenth day, when there were signs of extension to the right lower lobe. During the four days of serum treatment, the immature polymorphonuclears increased, but decreased on the eleventh day. The fever became continuous instead of remittent. On the twelfth day there were signs of pericarditis, and on account of the extreme cyanosis the patient was placed in the oxygen tent for four days. Fluid was detected in the right pleural cavity 
on the eighteenth day. One liter of pus was evacuated and tidal drainage instituted. Culture of the empyema fluid showed heavy infection with $\beta$-hemolytic streptococci. On the nineteenth day the patient expectorated about $200 \mathrm{cc}$. of sputum, and the signs of pericardial effusion disappeared within two days. On the twenty-fourth day the roentgen-ray showed signs of cavitation in the right upper lobe, and there was continuous expectoration of pus which contained many spirochetes and $\beta$-hemolytic streptococci. After postural drainage and the intravenous injection of neoarsphenamine, the lung abscess gradually healed and the patient gradually improved. He was discharged well on September 30, 1931.

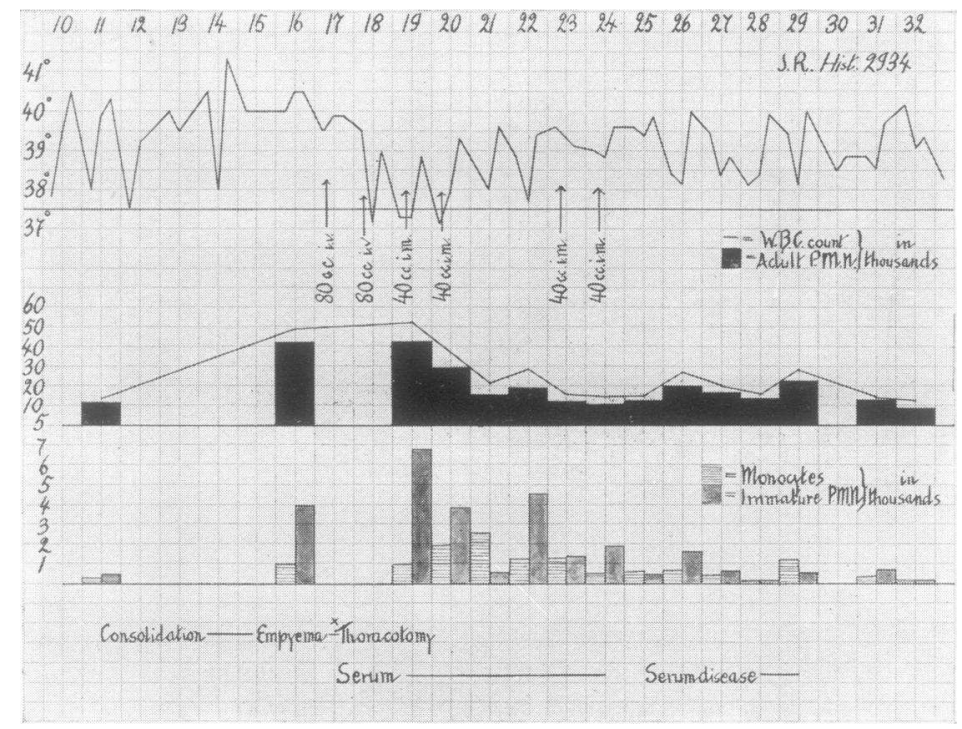

Chart II. Case III

Casc III. J. R., male, aged sixteen years, was admitted, January 27, 1931, from the infirmary on the tenth day of a very severe laryngitis with a high fever and unproductive cough. On the eleventh day there were signs of consoliclation in the left lower lobe. On the fifteenth day there were signs of fluid al the left base and cultures of the sputum taken on this date showed innumerable $\beta$-hemolytic streptococci. On the sixteenth clay there was a rise in the immature polymorphonuclear cells in the blood; and fluid containing large numbers of pus cells (culture positive for $\beta$-hemolytic streptococci) was removed from the pleural cavity. On the seventeenth day the patient became much worse. On this day $80 \mathrm{cc}$. of erysipelas anti-streptococcus serum were given intravenously and the dose repeated the following day, and tidal drainage of the pleural cavity was begun. On the succeeding six days there were given four injections of $40 \mathrm{cc}$. each of the concentrated serum intramuscularly. The number of immature polymorphonuclear cells began to recede on the twentieth day, and the patient began to improve. Convalescence was slow, but the patient was discharged well on May 15, 1931. 


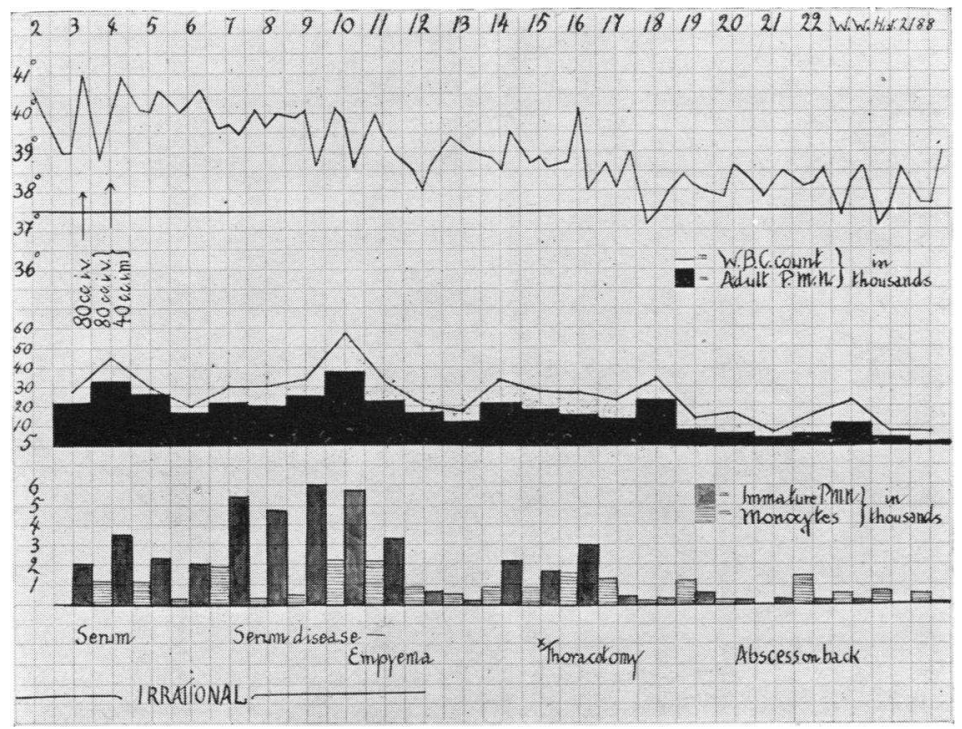

Chart III. Case IV

Case IV. W. W., male, aged fifteen years, about January 15, 1931, experienced a soreness in his throat, and the following day was admitted to the infirmary, where he was placed in the same room with several patients ill with influenza. About January 30th he had a chill and became very ill. Signs of pneumonia over the entire right side of the chest appeared on February 1st, and he was transferred to the Medical Service. By February 2, 1931, the sputum contained pus and many $\beta$-hemolytic streptococci. The $\mathrm{x}$-ray showed diffuse peribronchial reaction throughout the right lobes, thickened pleura and a shadow obscuring the outer portion of the diaphragm. The patient was irrational, the temperature varied from $39^{\circ}$ to $41^{\circ} \mathrm{C}$. and the blood pressure was 80 systolic and 40 diastolic. Eighty cubic centimeters of erysipelas antistreptococcus serum were given intravenously and the treatment repeated the following day with $40 \mathrm{cc}$. of the concentrated serum intramuscularly. The temperature, which had fluctuated markedly, began to be continuously high and gradually to recede. Serum disease appeared on the seventh day and the immature polymorphonuclears increased. One hundred cc. of fluid were withdrawn from the right pleural cavity on the tenth day, but tidal irrigation was not begun until the fifteenth day. Cultures of fluid showed heavy growth of $\beta$-hemolytic streptococci. The Schilling count shifted to the right, and there was a gradual and complete recovery. The patient was discharged well on April 4, 1931.

\section{Cases treated by intrapleural injection of serum}

In three of the four cases already described, empyema developed requiring long drainage. In the two cases to be described, the serum was injected into the pleural cavity with a twofold purpose $(a)$ as a mechanical method of affording relief from severe pleurisy and $(b)$ to prevent, if possible, empyema. In these cases the intravenous and intramuscular injections were also given. 


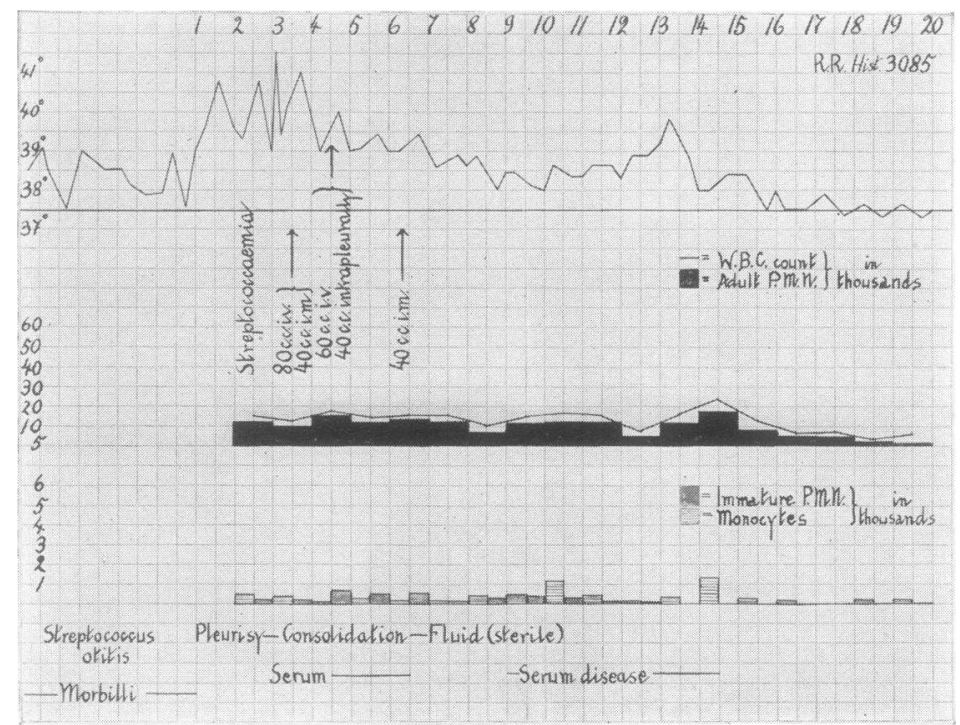

Chart IV. Case V

Casc $V$. R. R., male, aged eighteen years, was admitted February 7, 1931, with a draining ear following an attack of measles. He had suddenly developed a marked pleurisy with increase in fever, and the following day signs of consolidation were present at the area of the left scapula. Blood culture and culture of pus from left ear were both positive for $\beta$-hemolytic streptococci. $X$-ray showed infiltration radiating outward and downward from the left hilum throughout the left lower lobe, an area of consolidation in the right upper lobe, and thickening of the right interlobar pleura.

He became worse on the third day, and as the sputum contained $\beta$-hemolytic streptococci, $80 \mathrm{cc}$. of antistreptococcus hemolyticus serum were given intravenously and $40 \mathrm{cc}$. of concentrated serum intramuscularly.

On the fourth day (February 9), the pleurisy increased and spread into the lower left axilla, where there was an audible friction rub. At 11 p.m. of this day thoracentesis in the left axilla yielded $10 \mathrm{cc}$. of sanguineous fluid which contained pus cells but remained sterile on culture. After removal of the fluid there was injected slowly through the needle in place a mixture of $20 \mathrm{cc}$. of concentrated erysipelas antitoxin, $20 \mathrm{cc}$. of unconcentrated antistreptococcic serum hemolytic and $40 \mathrm{cc}$. of isotonic salt solution. Severe pain followed the injection, but the patient became comfortable after $10 \mathrm{mgm}$. of morphia. At 1 a.m. on February 10th, $60 \mathrm{cc}$. of antistreptococcic serum hemolytic with an equal amount of salt solution were injected intravenously. The temperature, which had reached $41.4^{\circ} \mathrm{C}$. on the morning before, began to recede and the patient felt much improved. On February 11 th there was considerable improvement, and the temperature and leukocyte count continued to decline, but there were signs of considerable fluid in the left pleural cavity. To maintain the concentration of antibodies $20 \mathrm{cc}$. of concentrated and $20 \mathrm{cc}$. of unconcentrated serum were injected intramuscularly at $10 \mathrm{p} . \mathrm{m}$. The fluid in the left pleural cavity was absorbed quickly for on February 12th the signs of fluid were absent, and the $\mathrm{x}$-ray showed " no evidence of fluid, but the diaphragm was slightly 





hazy." The temperature became normal on February 15th, and he made an uneventful recovery save for severe serum sickness. The patient was discharged well on March 14th.

Case VI. White male, aged forty-eight years, admitted on February 1, 1932, with the diagnoses of pernicious anemia and subacute combined sclerosis of spinal cord. He was treated with liver and liver extract, and was discharged improved on February 14th.

He continued to take liver extract irregularly, and was readmitted on November 18, 1932, with more advanced spinal cord changes and a neurological bladder. There had been only a moderate diminution in the erythrocyte count and hemoglobin.

On the eleventh day after admission his temperature rose to $39^{\circ} \mathrm{C}$. and the leukocyte count to 14,500 . Examination disclosed nothing to account for the fever. The irregular fever, rising to $38.5^{\circ}$ to $39.5^{\circ} \mathrm{C}$. daily, continued, and on December 7 th the patient complained of severe pain in the right flank and along the lower right anterior costal margin. Respirations were shallow and there was diminished excursion on the right. Tactile fremitus was moderately increased from the angle of the scapula to the right base. The percussion note was slightly impaired, and a loud, rough, friction rub obscured the breath sounds. On the following morning, the breath sounds were tubular and the friction rub was still present. The patient was acutely ill and was very uncomfortable. Culture of the sputum showed heavy growth of $\beta$-hemolytic streptococci. With the appearance of the fluid at the right base, the audible rub disappeared, but the severe pain endured. The blood culture, taken on December 8th, showed one colony of $\beta$-hemolytic streptococci per cubic centimeter. On December 9th, from the right pleural cavity, $400 \mathrm{cc}$. of thin, bloody fluid were withdrawn which on culture yielded a heavy growth of $\beta$-hemolytic streptococci. Following thoracentesis $85 \mathrm{cc}$. of concentrated erysipelas streptococcus antitoxin, diluted with $85 \mathrm{cc}$. of physiological saline, were injected directly into the pleural cavity without immediate reaction. There was no increase in the pain.

On December 10th, $40 \mathrm{cc}$. of the antitoxin were given intramuscularly. On December 11th, $500 \mathrm{cc}$. of pleural fluid were again withdrawn and $40 \mathrm{cc}$. of concentrated streptococcus antitoxin injected. The fluid withdrawn was no longer bloody and cultures remained sterile. The leukocyte count of 37,000 on the day before injection of serum, fell to 24,000 on the following day and to 17,000 on the third day ( see Chart V). The fever, which during the height of the disease ranged between 38.5 and $40^{\circ} \mathrm{C}$., now fluctuated between 38 and $38.8^{\circ} \mathrm{C}$. The patient looked and felt much improved, although signs of considerable pleural effusion remained. The irregular fever continued. Thoracenteses on December 17th and 29th and January 13, 1933, yielded quantities of fluid from 40 to $500 \mathrm{cc}$. All were cultured and remained sterile. The temperature gradually fell to normal cluring the five weeks following serum injections. The patient was discharged on January 26,1933 , having been afebrile for two weeks but with evidence of a small amount of encapsulated fluid along the right lateral chest wall.

\section{Specific action of the serum}

In Case $V$ it is possible that the intrapleural instillation of serum prevented infection of the pleural fluid by streptococci and in Case VI the serum apparently assisted within forty-eight hours in the removal of the growth already established. 
As evidence that the effect of the serum is a result of specific action rather than a non-specific provocation of reticuloendothelial cells (2), two cases are described below in which the pleural fluid contained, in addition to the $\beta$-hemolytic streptococcus, a strain of pneumococcus, Group IV. After adequate doses of the serum, streptococci were no longer present but the pneumococci endured.

Case VII. A six year old colored female was admitted to the Pediatric Ward ${ }^{5}$ on January 11, 1933, on the seventh day of lobular pneumonia and with signs of fluid in the left pleural cavity. The temperature was $40.5^{\circ} \mathrm{C}$. and white blood cells 20,500 per cubic millimeter. Sputum yielded pure culture of $\beta$-hemolytic streptococci and the blood culture showed less than one colony per cc of the same strain. Thoracentesis immediately after admission yielded a small quantity of sanguineous fluid which, on culture, had a heavy growth of $\beta$-hemolytic streptococci. The patient grew progressively worse. On January 15th and 16th, 15 and $40 \mathrm{cc}$. of fluid respectively were withdrawn and cultures were heavily positive. On January 17 th following aspiration of $30 \mathrm{cc}$. of fluid $10 \mathrm{cc}$. of erysipelas antitoxin were instilled into the pleural cavity. There was no reaction. On January 20,1933, $40 \mathrm{cc}$. of erysipelas antitoxin were injected intrapleurally following aspiration of $280 \mathrm{cc}$. of pleural exudate. Culture of this aspirated fluid again yielded $\beta$-hemolytic streptococci. Cultures of fluid removed on January 25 th and 27 th were negative for hemolytic streptococci, but gave a heavy growth of pneumococcus, Group IV. Before serum was given the temperature reached daily peaks of $39^{\circ}$ to $40.6^{\circ} \mathrm{C}$. and the white blood count 25,000 . Following the serum injections, the white blood count dropped rapidly to 12,000 and the peaks of fever to $38.5^{\circ}$ to $37.2^{\circ} \mathrm{C}$. After thoracenteses on January 25th and January 27th (yielding Group IV pneumococci) the temperature again rose to $40.6^{\circ} \mathrm{C}$.

Thoracotomy, for the purpose of tidal irrigation, was performed on January 30,1933 . Pus obtained at operation gave a pure culture of pneumococcus, Group IV.

Sputum culture now gave a mixed growth of pneumococcus, Group IV, staphylococcus aureus, and $\beta$-hemolytic streptococci. Blood cultures remained sterile.

Four days after operation the temperature fell to $37.6^{\circ} \mathrm{C}$. and remained normal until March 13th, when the drainage tube was removed. There was an immediate rise in temperature to $39.3^{\circ} \mathrm{C}$. and the child became quite ill again. Drainage was re-instituted and the temperature came to normal after six days. At discharge, March 24, 1933, the thoracotomy wound had healed, and the child was discharged in excellent condition.

Case VIII. Colored male, aged four years, brother of patient described under Case VII, admitted on January 11, 1933, on the fifth day of lobular pneumonia of left lung with pleurisy, thickened pleura and early empyema. Temperature $40.2^{\circ} \mathrm{C}$., white blood cells 11,600 ; sputum yielded a heavy growth of $\beta$-hemolytic streptococci and the blood culture showed less than one colony Fer cc. of the same organism. Thoracentesis on the day of admission yielded a small quantity of sanguineous fluid which, on culture, had a heavy growth of $\beta$-hemolytic streptococci.

${ }^{5} \mathrm{We}$ are greatly indebted to Dr. W. C. Davison, Professor of Pediatrics, for permission to report Cases VII and VIII and to Dr. Jean D. Craven, Resident in Pediatrics, for the clinical observations on them. 
During the succeeding nine days the child was acutely ill with daily peaks of fever to $39^{\circ}$ or $40^{\circ} \mathrm{C}$. The white blood cells ranged between 10,000 and 19,600. On January 20th, the seventeenth day of illness, thoracentesis was again performed and $50 \mathrm{cc}$. of fluid removed. Following aspiration $12 \mathrm{cc}$. of erysipelas antitoxin were injected intrapleurally. The aspirated exudate again yielded a heavy growth of $\beta$-hemolytic streptococci. On January 25 th aspiration of $100 \mathrm{cc}$. pleural fluid was followed by the intrapleural injection of $20 \mathrm{cc}$. of erysipelas antitoxin. Cultures of the aspirated fluid were negative for $\beta$-hemolytic streptococci, but yielded a heavy growth of pneumococci, Group IV.

Following the first intrapleural injection of serum on January 20th, the temperature was somewhat lower, showing daily peaks of 38 or $39^{\circ} \mathrm{C}$. The white blood count ranged between 8,800 and 9,400. On January 25th, however, coincident with the appearance of Group IV pneumococci in the pleural exulate, the temperature rose to $40.2^{\circ} \mathrm{C}$. and the white count to 12 to 14 thousand. The high temperature continued until tidal irrigation was instituted on February 8,1933 , the thirty-sixth day of the disease. Subsequent cultures of the pleural exudate continued to show Group IV pneumococci but no streptococci. Sputum cultures on January 2\% th showed a mixed growth of pneumococcus, Group IV, staphylococcus aureus and $\beta$-hemolytic streptococci. The temperature fell to normal five days after drainage was begun, and, except for a temporary rise to 39.2 to $39.8^{\circ} \mathrm{C}$. on March 17 th and 18 th, remained normal thereafter until discharge on March 25th. At the time of discharge there was still slight drainage from the sinus tract, but $x$-ray examinations showed no intrapleural fluil. The patient's general condition was excellent.

\section{Immunologic basis for serum treatment}

Antigens representing the $M$ (protein specific fraction) factor of Lancefield were prepared from each of the strains obtained from the sputum of the patients and tested against hyperimmune monovalent rabbit serum representing the strains used in the preparation of the antierysipelas serum. The results are recorded in Table I.

TABLE I

Lancefield precipitins, $M$ factor

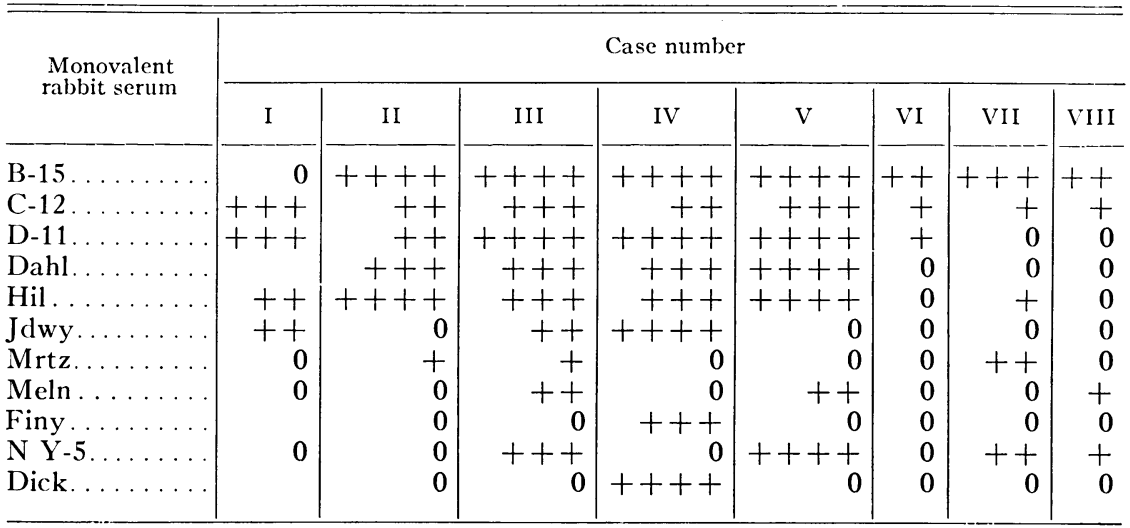


Skin neutralization tests ${ }^{6}$

The streptallergin from four strains ( Cases II to V) gave a positive skin reaction in goats. The addition of $0.1 \mathrm{cc}$. of serum from a goat immunized with the New York 5 scarlet strain of $\beta$-hemolytic streptococcus prevented any reaction in the presence of 10 skin-test doses of the streptallergins.

\section{Protection tests ${ }^{\top}$}

The virulence of four of the strains was increased by mouse passage until the minimum lethal dose became $0.5 \mathrm{cc}$. of $10^{-\tau}$ dilution.

The protection tests were made by injecting intraperitoneally $0.2 \mathrm{cc}$. of the anti-serum diluted to $0.5 \mathrm{cc}$. with isotonic salt solution, and simultaneously but separately $0.5 \mathrm{cc}$. of the dilution of the eighteen-hour broth culture of the organism. Three mice were used for each dilution and a virulence control and normal horse serum control were injected in each series.

The results of the protection tests were as follows:

Case I. Not tested.

Case II. Virulence $10^{-6}$; Mulford's concentrated protected against $10^{-5}$; unconcentrated ; result inconsistent; New York State, no protection.

Case III. Virulence $10^{-6}$; Mulford's concentrated protected against $10^{-5}$; unconcentrated: result inconsistent; New York State, no protection.

Case IV. Virulence $10^{-6}$; Mulford's concentrated protected 2 out of 3 against $10^{-4}$; unconcentrated protected against $10^{-5}$; New York State, no protection.

Case V. Control: 2 out of 3 mice died after injection of $10^{-5}$ dilution plus normal horse serum. Mulford's concentrated streptococcus antitoxin protected all mice against $10^{-3}$; New York State antistreptococcus serum protected 2 mice out of 3 against $10^{-5}$.

Cases VI, VII and VIII : strains azirulent for mice.

Protection tests with convalescent serum from the patients have not yet been made.

\section{DISCUSSION}

The patients treated with serum were critically ill. With the high fever, cherry cyanosis, hypotension, distension, and evidences of a rapidly spreading lesion, the prognosis was very grave. In Case I the administration of the serum was followed by a marked increase of urinary secretion and quick disappearance of fever with a definite improvement in the

${ }^{6}$ These tests were made by Miss Ruth Wheeler of the New York State Laboratory of Hygiene, to whom we are greatly indebted for her cooperation.

'Method of Mr. C. Roos, Glenolden, Pa. 
patient's general condition. It is not possible to conclude that the serum assisted in producing these effects but certainly no harm was done. In Cases II, III and IV there was no dramatic response in any way. The temperature curve showed no immediate change except a tendency to be stabilized at the peaks, without oscillation, and with a gradual descent. The leukocyte count and Schilling differential did not indicate signs of improvement for two or three days. Thus observing the charts there were no definite indications that the serum conferred any beneficial effect, but in watching the patients all observers agreed that there was a gradual improvement beginning a few hours after the first dose of serum. The survival of eight successive cases of hemolytic streptococcus pneumonia has not happened in our ten years of clinical experience in infectious diseases.

In Cases V and VI treated by the instillation of the serum into the pleural cavity there is definite bacteriological evidence of the effect of the serum in preventing and clearing up the infection of the pleural exudate. In Cases VII and VIII there is evidence that the effect is specific, as shown by the fact that the hemolytic streptococci disappeared after adequate doses of serum, but the pneumococci remained. In these two cases there was a decided and marked clinical improvement with relief from symptoms of toxemia after the streptococci disappeared from the chest fluid although the pneumococcic infection enclured.

The question naturally arises as to the virulence of streptococcus infections in the latitude of North Carolina. Apparently streptococcic infections, with the exception of scarlet fever, are as serious in this hospital as in more northerly regions.

The accessory investigations reported show definitely that the treatment of $\beta$-hemolytic streptococcus pneumonitis has a logical immunological basis but whether the serum treatment is valual)le remains to be determined under conditions where controlled series are possible.

\section{CONCLUSIONS}

1. Eight successive patients admitted with $\beta$-hemolytic streptococcic lobular pneumonitis were treated with antistreptococcic serum and all surviverl.

2. Three out of four patients treated by intravenous and intramuscular injections of the serum developed streptococcal empyema.

3. Instillation of the serum into the pleural cavity in two cases with effusion apparently prevented infection of the fluid in one case and in the other case cleared the infected fluid of organisms in forty-eight hours.

4. Instillation of the serum into the pleural cavity in two cases admitted with empyema cleared the fluid of the hemolytic streptococcus but not of the pneumococcus. Group IV, which appeared simultaneously with the disappearance of the streptococci.

5. The results of tests by precipitins, toxallergin neutralization and 
mouse protection tests suggest a rational immunologic basis for specific serum treatment.

\section{BIBLIOGRAPHY}

1. Lancefield, Rebecca C., J. Exper. Med., 1928, xlvii, 91, and ibidem, 469. The Antigenic Complex of Streptococcus Hemolyticus. I. Demonstration of a Type Specific Substance in Extracts of Streptococcus Hemolyticus.

2. Gay, F. P., and Clark, A. R., J. Exper. Med., 1930, lii, 95. Enhanced Passive Immunity to Streptococcus Infection in Rabbits. 